\title{
The Long Non-coding Road to Atherosclerosis
}

\author{
Tatjana Josefs $^{1} \cdot$ Reinier A. Boon ${ }^{1,2,3}$ (D)
}

Published online: 9 August 2020

(C) The Author(s) 2020

\begin{abstract}
Purpose of Review To summarize recent insights into long non-coding RNAs (lncRNAs) involved in atherosclerosis. Because atherosclerosis is the main underlying pathology of cardiovascular diseases (CVD), the world's deadliest disease, finding novel therapeutic strategies is of high interest.

Recent Findings LncRNAs can bind to proteins, DNA, and RNA regulating disease initiation and plaque growth as well as plaque stability in different cell types such as endothelial cells (ECs), vascular smooth muscle cells (VSMCs), and macrophages. A number of lncRNAs have been implicated in cholesterol homeostasis and foam cell formation such as LASER, LeXis, and CHROME. Among others, MANTIS, IncRNA-CCL2, and MALAT1 were shown to be involved in vascular inflammation. Further regulations include, but are not limited to, DNA damage response in ECs, phenotypic switch of VSMCs, and various cell death mechanisms. Interestingly, some lncRNAs are closely correlated with response to statin treatment, such as NEXN-AS1 or LASER. Additionally, some lncRNAs may serve as CVD biomarkers.

Summary LncRNAs are a potential novel therapeutic target to treat CVD, but research of lncRNA in atherosclerosis is still in its infancy. With increasing knowledge of the complex and diverse regulations of lncRNAs in the heterogeneous environment of atherosclerotic plaques, IncRNAs hold promise for their clinical translation in the near future.
\end{abstract}

Keywords lncRNA · Atherosclerosis · Cardiovascular disease

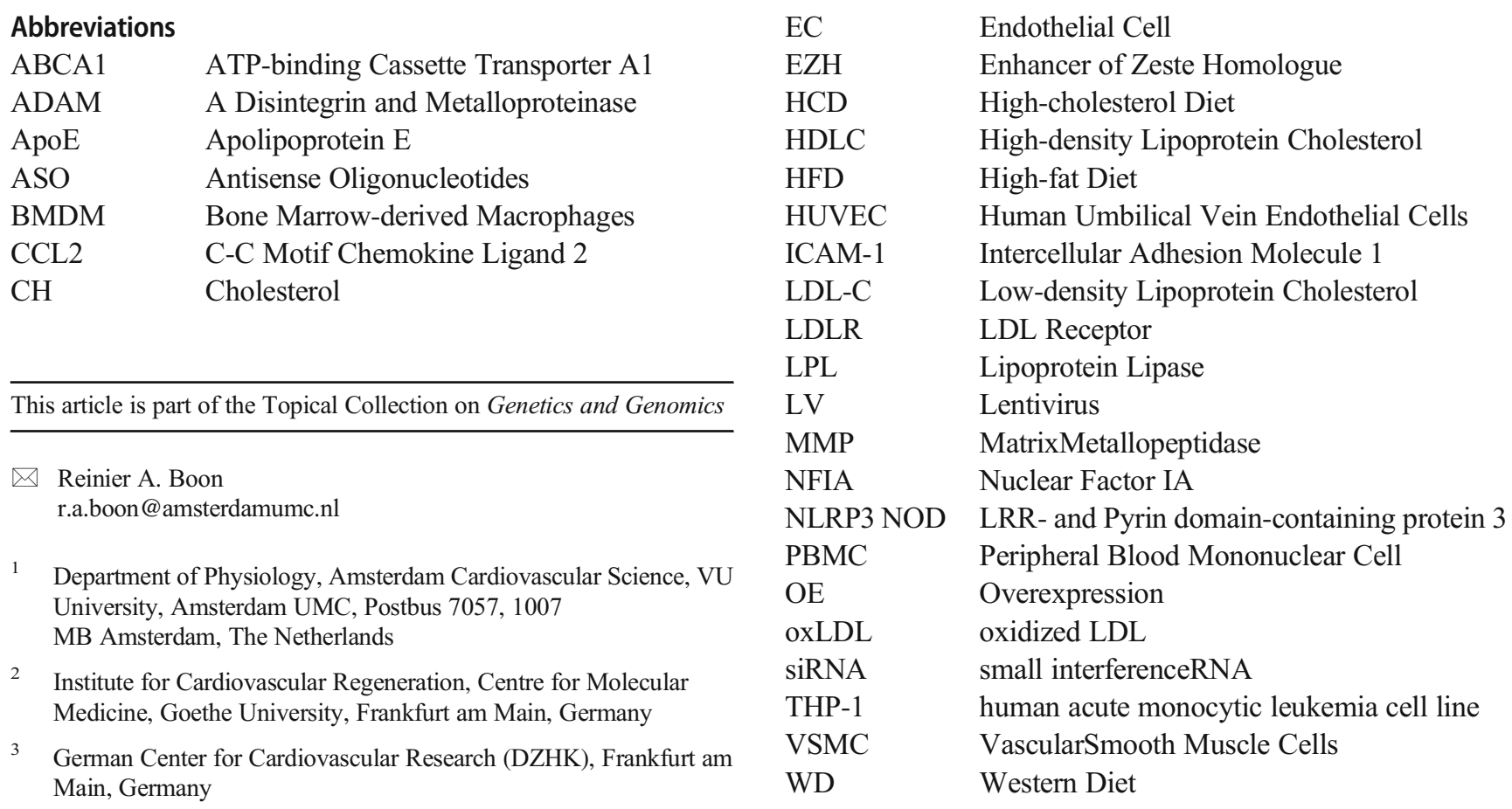




\section{Introduction}

The fate of atherosclerosis is dependent on the phenotype of a variety of highly plastic cells in atherosclerotic plaques, and their myriad functions are transcriptionally and posttranscriptionally regulated in response to environmental stimuli. With advances in genomic tools, a new variable for gene regulation, namely non-coding RNA (ncRNA), has been introduced. This previously considered "evolutionary junk" makes up the majority of the transcribed human genome with only $2 \%$ being transcribed as RNA encoding proteins $[1,2]$. Accumulating evidence shows that ncRNAs contribute to the regulation of networks in physiological and pathophysiological mechanisms, including those of cardiovascular diseases (CVDs).

CVDs are responsible for the majority of morbidity and mortality worldwide, and despite developments in scientific discoveries, clinical cardiology and public health leading to improved outcomes in patients who suffered CV events, its prevalence is still expected to rise [3-5]. Thus, novel strategies to diagnose, prevent, and treat CVD are desperately needed.

Early GWAS gave first insights into the importance of ncRNA in CVD, defining the most significantly associated locus with coronary artery diseases (CAD) - Chr9p21-to contain a stretch of 58 kilobases $(\mathrm{kb})$ of ncRNAs [6-9]. The locus was shown in subsequent studies to associate with atherosclerosis [10-12] and different atherosclerosis endpoints such as myocardial infraction, stroke andaneurysms [8, 13-19]. Over the past decade, the number of CAD risk loci rose from originally 9 [6] to 243 in 2017 [20].

While early research in the field of ncRNA focused on principal RNA participants in gene expression, namely messenger, ribosomal, and transfer RNAs, research interest expanded to micro RNAs (miRNA) in early 2000 . Novel genomic technologies including the availability of fast and costeffective sequencing technologies as well as computational resources, opened up the field for long ncRNA (lncRNA) and circular RNA (circRNA) [21]. Multiple lncRNAs have been described to play a role in atherosclerosis, the main underlying pathology of CVD. Thereby, IncRNAs are implicated in several atherogenic processes, such as endothelial dysfunction, lipid deposition, and inflammation, and have been shown to be expressed in different cell types known to be present in atherosclerotic lesions (e.g., endothelial cells (ECs), vascular smooth muscle cells (VSMCs), macrophages).

LncRNAs still lack a clear classification but are generally defined as ncRNA $>200$ nucleotides (nt) long and make up the largest part of ncRNA [22]. However, up to date, fewer than $5 \%$ have been characterized, partly due to poor conservation among species $[23,24]$. While lncRNAs by definition have no protein coding potential, hence mostly lack functional initiation and termination codons [25], some lncRNAs have surprisingly been found to translate into micropeptides [26,
27], complicating the classification of IncRNAs further. Although the lncRNA classification is still unclear, it became apparent that this heterogeneous group of ncRNA can bind to DNA, RNA, proteins, or a combination thereof, likely due their capacity to fold into various thermodynamically stable structures [28].

This review aims to summarize recent studies on lncRNAs in the field of atherosclerosis and is divided into their binding ability with proteins, DNA, and RNA.

\section{Mechanisms of IncRNAs}

LncRNAs are present in the nucleus and in the cytoplasm and therefore are able repress and activate genes on transcriptional and post-transcriptional levels. According to their position on the genome and adjacent genes, IncRNAs can be classified as sense, antisense, bidirectional, intronic, or intergenic lncRNAs and act in cis or trans (regulating genes in close proximity or further away, respectively). According to their functions, lncRNAs can also be classified as signaling, decoy, guide, and scaffold lncRNAs, while one lncRNA can have multiple archetypes [29].

Transcriptional regulatory mechanisms include interaction with chromatin-modifying complexes, transcriptional regulators, and DNA [30]. These interactions can either repress or activate gene expression, depending on the nature of enzymes bound to chromatin complexes and the type of function for interacting lncRNA. If transcribed in response to stimuli, socalled signaling lncRNAs serve as molecular signals and regulate gene expression via one of the mechanisms described below. Their transcription is time and location specific [31]; and thus, their presence may also reflect cell condition, state, and transcriptional activity. Decoy lncRNAs can impair the interaction of transcriptional regulators with their target genes by, for instance, mimicking DNA-binding sites, and impair downstream effector functions. Guide lncRNAs on the other hand can enhance downstream effector functions by aiding localization of transcriptional regulators to specific regions. Additionally, lncRNAs can mediate protein-protein interactions resulting in organization of nuclear subdomains, e.g., polycomb group proteins (scaffold lncRNAs). By direct RNA-DNA interaction, IncRNAs can display enhancer-like activity (enhancer RNA; eRNA) or form RNA-DNA triplex structures repressing gene expression via blocking the assembly of the pre-initiation complex. Not only the presence of lncRNAs but also its transcription can modify mRNA expression. Like mRNAs, lncRNAs are believed to be mainly transcribed by RNA polymerase II (Pol II) [25, 32] and Pol IIbound chromatin-modifying complexes can deposit histone modifications while moving along the DNA locus. Further, IncRNA transcription-dependent chromatin modifications can also affect binding affinity for regulatory factors. 
Post-transcriptional regulatory mechanisms include the interference with pre-mRNA splicing and both positive and negative implications on mRNA translation/stability. For instance, antisense lncRNAs can upregulate mRNA translation through interaction with the 5'region of mRNA, while binding of Alu-element containing IncRNA to mRNA Alu-elements at the 3'UTR results in Staufen-mediated decay of the mRNA. Further, direct or indirect interaction of lncRNAs with miRNAs has regulatory effects by either masking miRNA binding sites on target mRNA or by miRNA sequestration (competitive endogenous RNA).

Finally, several recent publications show that some transcripts annotated as IncRNA actually function as mRNAs and produce small proteins $[27,33]$, making the determination of the exact mechanism by which a lncRNA elicits its effect complex.

\section{LncRNA-Protein Interactions in Atherosclerosis}

LncRNAs are able to regulate epigenetic changes, transcription, alternative splicing, and translation via the modulation of protein activity, localization, and structure (Fig. 1).

LncRNA LASER (Lipid Associated Single nucleotide polymorphism gEne Region) binds to LSD1 (lysine-specific demethylase; member of CoREST/REST complex), leading to decreased $\mathrm{H} 3 \mathrm{~K} 4 \mathrm{me}$ demethylation at the promoter region of the HNF- $1 \alpha$ gene and subsequently to increased PCSK9 (Proprotein convertase subtilisin/kexin type 9) expression in hepatocytes [34]. As PCSK9 directs low-density lipoprotein receptors (LDLR) towards degradation, LASER expression is positively correlated with circulating cholesterol levels (total cholesterol, LDL, apoB100) in vitro and in vivo as well as

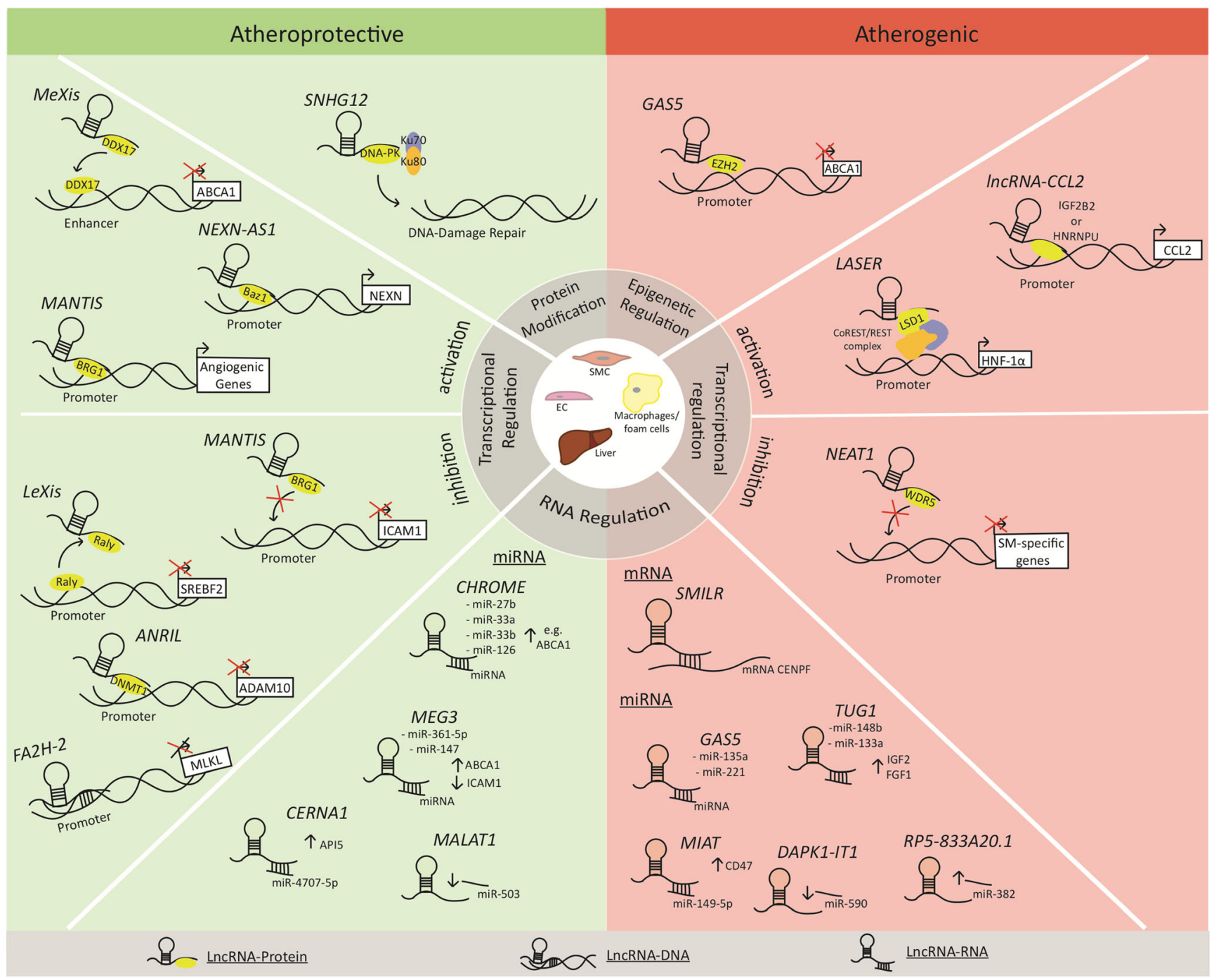

Fig. 1 Atheroprotective and atherogenic mechanisms of lncRNAs 
with PCSK9 in statin-free patients. Statin $(=\mathrm{HMG}-\mathrm{CoA}$ reductase inhibitor) treatment lowers circulating atherogenic lipids via blocking cholesterol biosynthesis in the liver and increases $L A S E R$ expression. Hence, its expression is regulated by a cholesterol-mediated feedback loop and represents a potential target to augment the effect of statin treatment. Also implicated in cholesterol homeostasis is LeXis (Liverexpressed Liver X Receptor (LXR)-induced sequence) [35], a lncRNA that binds the ribonucleoprotein RALY in hepatocytes, and inhibits its occupancy at cholesterol biosynthetic gene promoters, such as Srebf2. Using a liver-specific adeno-associated virus (AAV8)-based gene approach to increase LeXis expression in western diet (WD)-fed $\mathrm{Ldlr}^{--}$ mice was associated with a decrease in hepatic and circulating lipid levels and reduced atherosclerosis [36]. This indicates that the LeXis-mediated crosstalk between LXR and sterol regulatory element binding protein (SREBP) transcription factors could therapeutically be harnessed to maintain cholesterol homeostasis in CVD risk patients.

While regulating the secretion of atherogenic lipoproteins from the liver into the circulation is a central step in maintaining cholesterol homeostasis, thus preventing pathogenic deposition of these lipoproteins in the artery wall, another pivotal process is the removal of excess cholesterol from atherosclerotic plaques. Cholesterol efflux represents the first step of the reverse cholesterol transport (RCT) and is done to nascent apolipoprotein $\mathrm{A} 1$ via $\mathrm{ABCA} 1$ transporter or to mature highdensity lipoprotein (HDL) via ABCG1/SR-B1 transporter [37], followed by its delivery to the liver and its excretion via the bile. One lncRNA that amplifies LXR-mediated Abcal expression is lncRNA MeXis (Macrophage-expressed LXR-induced sequence) by guiding the transcriptional coactivator DDX17 to Abca1 enhancer regions [38]. In line, cholesterol efflux was increased in LXR-stimulated MeXis-expressing RAW cells, while lack of MeXis in bone marrow (BM) cells of WD-fed $\mathrm{Ldlr}^{-1-}$ mice accelerated atherosclerosis progression measured as lesion size and lipid content, compared with wild-type BM. LncRNA ANRIL (antisense non coding RNA in the INK4 locus) was reported to promote cholesterol efflux [39]. Mechanistically, ANRIL can function as scaffold lncRNA by recruiting DNA methyltransferase 1 (DNMT1) to the ADAM10 promoter, enhancing its methylation. The suppression of ADAM10 expression through overexpression of ANRIL in THP1 macrophage-derived foam cells and apolipoprotein E-deficient $\left(\mathrm{ApoE}^{-/}\right)$mice showed increased cholesterol efflux and decreased lesion area. Of note, ANRIL has been extensively studied and reviewed elsewhere [40]. In contrast to promoting cholesterol efflux, lncRNA GAS5 inhibited Abcal expression by binding the enhancer of zeste homologue 2 (EZH2), which in turn promotes triple methylation of lysine 27 (H3K27). Therefore, IncRNA GAS5 reduced cholesterol efflux in THP-1 macrophage-derived foam cells and its knockdown decreased atherosclerosis progression in $\mathrm{ApoE}^{-/}$mice [41].
Next to lipid deposition, vascular inflammation initiates and drives atherosclerosis progression and is partly driven by activation of ECs through the NF-kB pathway [42]. Overexpression of IncRNA NEXN-AS1 (Nexilin F-actin binding protein antisense RNA 1) suppressed the TLR4/NF$\mathrm{kB}$ pathway and thereby reduced endothelial activation and monocyte recruitment in human vascular endothelial cells (HVEC) [43]. Further, its overexpression inhibited proinflammatory pryoptosis-related biomarkers known to drive atherosclerosis (NLRP3, caspase-1, IL-1 $\beta$, IL-18, GSDMD) [44]. Thereby, NEXN-AS1 upregulates the expression of the $N E X N$ gene by preventing chromatin condensation through binding the chromatin remodeler BAZ1A [43]. NEXN deficiency promoted atherosclerosis and plaque inflammation in WD-fed $A p o E^{-/}$mice, while NEXN overexpression prevented these effects [43]. Additionally, the expression of both - NEXN-AS1 and NEXN—is reduced in atherosclerotic arteries compared with healthy arteries in humans [43]. Further, atorvastatin significantly induced NEXN-ASI and NEXN expression, suggesting a new atheroprotective mechanism for statins non-lipid-lowering effects. IncRNA MANTIS (LncRNA n342419) also mediates vascular protection in trans via its interaction with SWI/SNF chromatin remodeling factor BRG1. This enables BRG1-promoter binding to angiogenic genes, such as SOX18 [45], and on the other hand, hinders BRG1 interaction with the promoter region of monocyte adhesion factor ICAM-1 [46]. As for NEXN-AS1, statins also increased MANTIS expression in human umbilical vein endothelial cells (HUVECs) and prevented reduced MANTIS expression in human artery endarterectomy compared with healthy vessels [46].

Although the majority of atherosclerotic plaque remain clinically silent, chronic inflammation and ongoing monocyte recruitment contribute to plaque growth and can feed into destabilization, thus, resulting in life-threatening acute events. One lncRNA found to be increased in unstable symptomatic compared with asymptomatic human atherosclerotic plaques was LncRNA-CCL2 [47]. LncRNA-CCL2 is upregulated in IL1- $\beta$-induced inflammatory HUVECs and regulates CCL2 mRNA levels in part through interaction with RNA-binding proteins in the nucleus, namely IGF2BP2 (insulin growth factor 2 binding protein 2) and HNRNPU [47]. The CCL2 gene encodes monocyte chemoattractant protein $1-$ a key mediator in inflammatory processes that facilitates monocyte recruitment and correlates with increased lncRNA-CCL2 expression in symptomatic plaques. VSMCs can also contribute to inflammation, monocyte recruitment, and plaque destabilization via a phenotypic switch from a contractile state to synthetic macrophage-like cells [48]. This process was shown to be promoted by lncRNA NEAT1 (nuclear paraspeckle assembly transcript 1) [49]. NEAT1 interacted with chromatin modifier WDR5 resulting in inhibited trimethylation at the promoters of genes encoding SM proteins. 
Independent of the effects on circulating lipid levels or vessel wall inflammation was the observed accelerated atherosclerosis in high cholesterol diet (HCD)-fed $\mathrm{Ldll}^{-/}$mice driven by the knockdown of lncRNA SNHG12 [50]. LncRNA SNHG12 (small nucleolar host gene-12) binds to DNA protein kinase (DNA-PK) in the vascular endothelium, which in turn facilitates binding of DNA-PKcs to Ku70/80 and the ability of DNA damage repair. Thus, $S N H G 12$ knockdown resulted in increased DNA damage and cellular senescence in vitro and in vivo, which exacerbated EC dysfunction and macrophage efferocytosis. Further, reduced SNHG12 expression in atherosclerotic specimen of pigs and human was inversely correlated with DNA damage and senescence.

\section{LncRNA-DNA Interactions in Atherosclerosis}

LncRNA-DNA interactions are diverse, and several mechanisms for how lncRNAs recognize specific target sites have been proposed including polymerase tethering, hybridization, and DNA-binding protein-mediated recruitment [51] (Fig. 1). The binding of lncRNA to specific DNA regions can lead to the recruitment of proteins regulating epigenetic modulations (described above) as well as to positive or negative gene expression. In the context of atherosclerosis, IncRNA $F A 2 H-2$ regulates autophagy and inflammation via binding the promoter of mixed lineage kinase domain-like protein (MLKL) gene. The subsequently suppressed MLKL expression increased autophagy flux and alleviated inflammatory damage induced by oxLDL in SMC and ECs [52]. Increased autophagy has been reported to be atheroprotective by preventing macrophages and smooth muscle cells to become foam cells and by alleviating inflammation [53-56], suggesting an atheroprotective role for lncRNA $F A 2 H-2$. Indeed, knock-

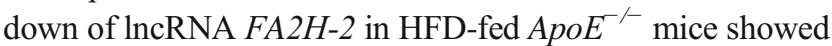
increased MLKL expression, reduced autophagy flux, and enhanced inflammation and lesion area [52].

\section{LncRNA-RNA Interactions in Atherosclerosis}

LncRNAs can be shuttled to the cytoplasm and modulate premRNA splicing, mRNA stability, miRNA availability, and/or protein translation [57] (Fig. 1). One example for IncRNAmRNA interaction is IncRNA SMILR (smooth muscleinduced lncRNA). SMILR did directly bind the mRNA of the mitotic protein CENPF (centromere protein F) and promoted the proliferation of VSMCs [58]. In agreement with VSMC proliferation conferring with plaque stability, increased SMILR levels were detected in unstable compared with stable human atherosclerotic plaques [59]. Thereby, SMILR may represent a valuable target to prevent adverse vascular remodeling after balloon angioplasty and vessel stenting.

The LXR-mediated IncRNA CHROME negatively regulates a number of miRNAs (miRNA miR-27b, miR-33a, miR-33b, miR-128) in human hepatocytes and macrophages [60]. One of the genes being post-transcriptional repressed by these miRNAs upon CHROME deficiency is Abcal. Thus, CHROME upregulates cholesterol efflux and HDL biogenesis, manifesting atheroprotective effects. Atherogenic outcomes via affecting cholesterol metabolism have been shown for IncRNAs RP5-833A20.1 [61], DAPK1-IT1 [62], and GAS5 [63-66]. RP5-833A20.1 induced hsa-miR-382-5p expression and in turn inhibited nuclear factor IA (NFIA) expression in macrophage-derived foam cells [61]. In vivo experiments using $\mathrm{ApoE^{-/ }}$ mice fed a high-fat/high-cholesterol diet confirmed the RP5-833A20.1/hsa-miR-382-5p/NFIA pathway and additional showed that overexpressing NFIA results in atheroprotective circulating lipoprotein changes, enhanced RCT, decreased circulating cytokine levels, and suppressed lesion formation. LncRNA DAPK1-IT1 decreased miR-590-3p expression and led to increased LPL expression and reduced cholesterol efflux in THP-1 macrophage-derived foam cells [62]. Elevated GAS5 (growth arrest-specific 5) levels are present in atherosclerotic plaque of human [66], rat [66], and mice [63] and promote inflammation, foam cell formation, and apoptosis as well as lipid disorders by interacting with miR-135a [63, 64] and miR-221 [65].

Another interesting lncRNA in atherosclerosis is MALAT1 (metastasis-associated lung adenocarcinoma transcript 1). MALAT1 regulates proliferation of ECs [67] and VSMCs [68] in vitro. Additional in vitro analyses revealed the interactions of MALAT1 with miR-216-5p [69] or miR-22 [70] to promote autophagy and pryoptosis, respectively. A recently published study elucidated the in vivo role of MALAT1 in atherosclerosis and demonstrated that MALAT1 exhibits anti-inflammatory properties in part by binding to miR-503 [71]. In detail, deficiency of IncRNA MALAT1 in hematopoietic cells leads to enhanced atherosclerotic lesion formation and inflammation in HFD-fed $A p o E^{-1}$ mice [71]. The acceleration of lesion formation was driven by an increase in inflammatory BM cell number and enhanced adhesion to ECs in vitro and atherosclerotic vessel wall in vivo. Further, enhanced adhesion of BM cells was rescued by inhibition of miR-503. In line, MALAT1 expression in human atherosclerotic plaque was downregulated in comparison to healthy vessel and, moreover, was decreased in symptomatic versus asymptomatic patients.

LncRNAs can also function as competitive endogenous RNA (ceRNA) regulating gene expression by sequestering miRNAs [72]. Although this concept has been questioned as computational analyses indicated the shortcoming of lncRNAs compared with the in excess expressed miRNA [73], several studies reported on IncRNA-miRNA interactions 


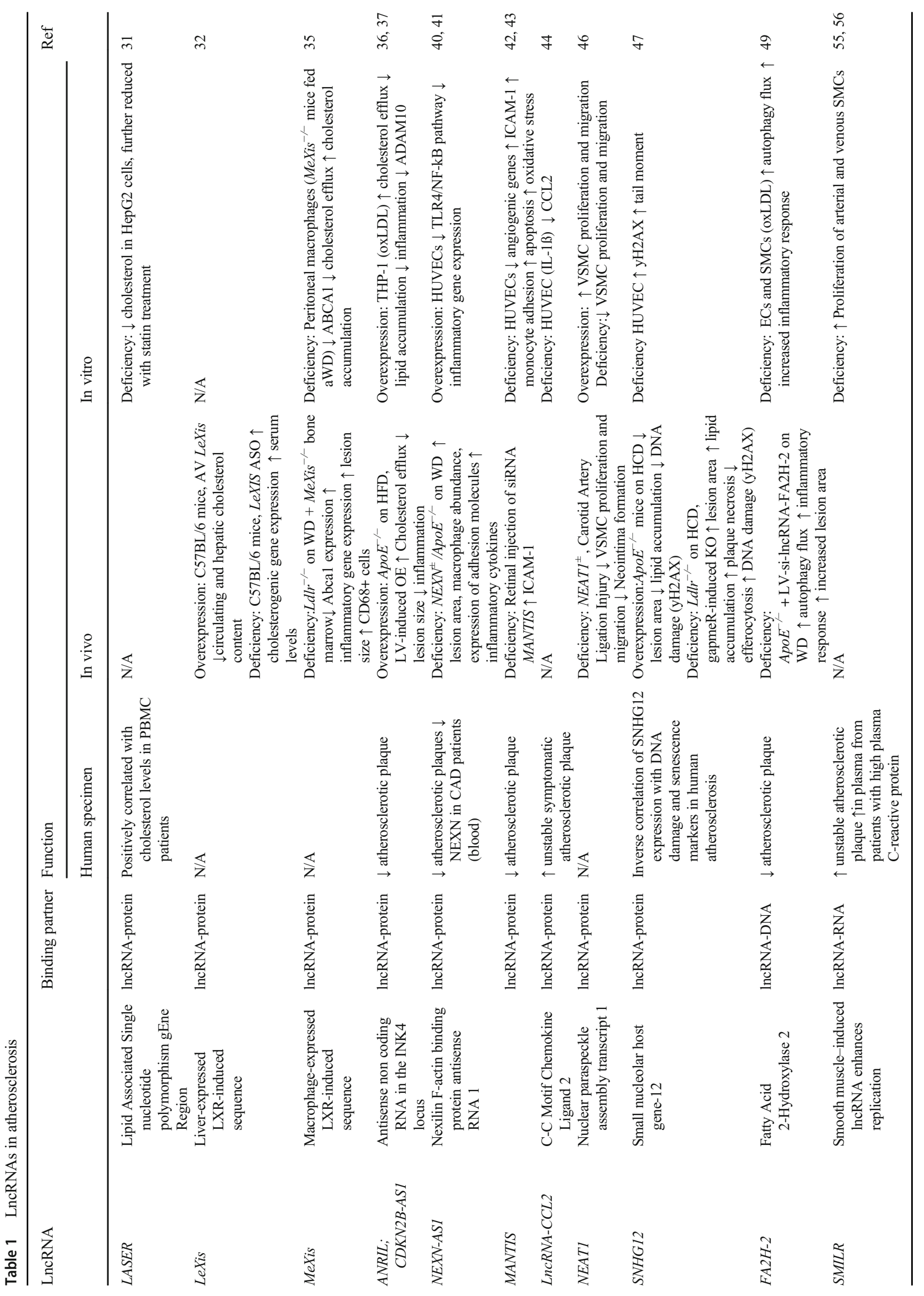




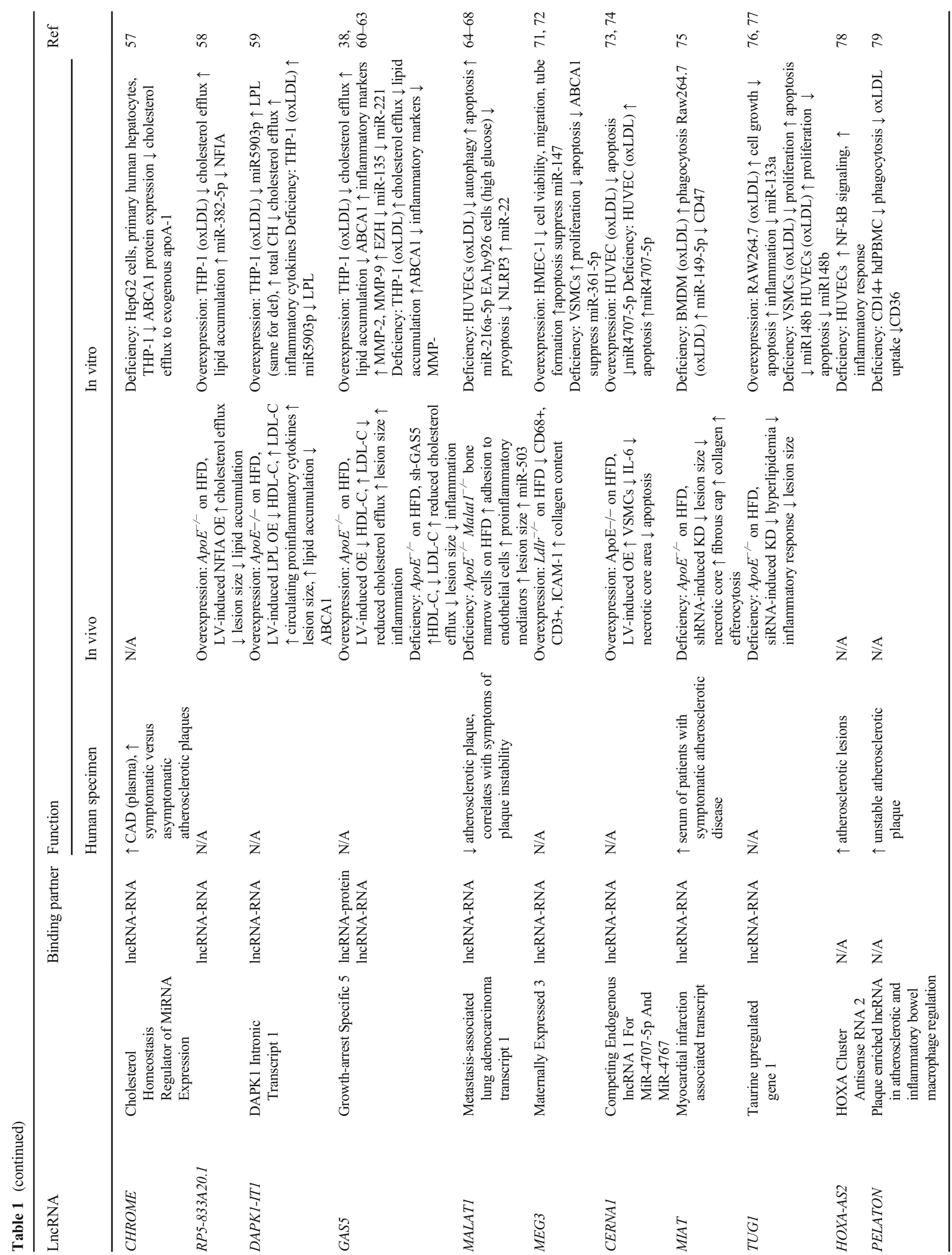


in the context of atherosclerosis. For example, lncRNA $M E G 3$ functions as sponge of miR-361-5p, regulating ABCA1 expression in VSMC [74] or the expression of ICAM-1 by sponging miR-147 [75]. Further, CERNA1 (Competing Endogenous lncRNA 1 For MiR-4707-5p And MiR-4767, previously LOC100129973) inhibited apoptosis of VSMC and anti-inflammatory macrophages through increasing the apoptosis inhibitor API5 via sponging miR-4707-5p [76, 77]. Thereby, CERNA1 overexpression in HFD-fed $A p o E^{-/}$ mice led to features of stable plaques, such as an increase in VSMCs and a decrease in MMP-2/9 activity, necrotic core area, and apoptotic cells. Another regulator of plaque vulnerability is lncRNA MIAT (Myocardial infarction associated transcript), which is upregulated in symptomatic human atherosclerotic specimen as well as in serum and plaques of HFD-fed $A p o E^{-/}$mice [78]. Deficiency of MIAT in atherosclerotic $A p o E^{-/}$mice improved efferocytosis, decreased apoptosis, and attenuated plaque growth. Mechanistically, MIAT acts as a sponge of miR-149-5p, subsequently inhibiting the mRNA degradation of the anti-phagocytic molecule CD47 in oxLDL-stimulated Raw264.7 cells. Moreover, lncRNA TUG1 (taurine-up-regulated gene 1) acts as sponge for miR$148 \mathrm{~b}$ in oxLDL-stimulated VSMC and HUVECs and regulated their proliferation and apoptosis via TUG1/miR-148b-promoted insulin growth-like factor 2 (IGF2) expression [79]. Another TUG1 target is miR-133a [80]. Sponging miR-133a in oxLDL-simulated Raw264.7 upregulated fibroblast growth factor 1 (FGF1) expression, in turn leading to increased proliferation, inflammation, and inhibited apoptosis. In line with the in vitro data, TUG1 knockdown in HFD-fed $A_{p o E^{-/}}$improved circulating lipid levels and inflammatory markers and reduced lesion size [80].

\section{Uncharacterized Interactions}

The mechanisms for two recently described lncRNAsHOXA-AS2 and PELATON-implicated in atherosclerosis are yet to be defined. For example, transcriptomic profiling of HUVECs with and without the expression of lncRNA HOXA-AS2 showed that HOXA-AS2 mediates expression of inflammatory factors [81]. Further experiments confirmed that HOXA-AS2 regulated endothelium inflammation by repressing NF- $K B$ signaling. At the same time, NF- $K B$ activity upregulated $H O X A-A S 2$, which is likely the reason for the highly increased expression of HOXA-AS2 in human atherosclerotic plaques [81]. However, how exactly lncRNA HOXA-AS2 regulates inflammatory marker and especially the feedback loop with NF-kB is not yet known. LncRNA PELATON (Plaque enriched lncRNA in atherosclerotic and inflammatory bowel macrophage regulation) was found to be implicated in plaque instability and is enriched in unstable compared with stable atherosclerotic plaques [82]. With its high nuclear expression in monocytes and macrophages, it was shown to regulate phagocytosis, oxLDL uptake, and ROS production in differentiated primary human monocytes, in part due to changes in CD36 expression. However, the underlying mechanism is yet to be elucidated.

\section{LncRNAs as Biomarkers in Atherosclerosis}

Finally, abundance of circulating lncRNAs or the occurrence of single nucleotide polymorphisms (SNPs) represents novel biomarkers for CVDs. Increased levels of lncRNAs H19 and LIPCAR were found in plasma and serum samples in a Chinese population with atherosclerotic disease [83, 84]. Further, IncRNA MIAT were detected to be elevated in the blood of ischemic stroke patients [85]. LncRNA SMILR seems to play a role in plaque stability [58], and its plasma levels positively correlate with C-reactive protein [59].

SNPs in the lncRNA MIAT promoter correlated with acute myocardial infarction in a Chinese Han population [86], while a specific polymorphism in MALAT1 (rs619586AG/GG) might be CVD protective [87].

\section{Conclusion}

Collectively, cited studies in this review (Table 1) show that dysregulated lncRNAs are becoming a hallmark of atherosclerosis and play a role in several atherosclerosis processes as well as cell types. It has thus become clear that lncRNAs with their ability to interact with protein, DNA, and RNA can dynamically regulate the numerous functions of a variety of plastic cells and thereby impact atherosclerotic plaque growth, inflammation, and stability. However, understanding the complex regulation of IncRNAs in atherosclerosis is still in its infancy. Despite a number of lncRNAs being described in atherosclerosis, these mainly entail in vitro functions and less is known in respect to their roles in vivo. The scope of elucidating its functions in vivo is limited by the low conservation between species and impedes the investigation of the most interesting primate-specific lncRNAs in the widely used atherosclerotic mouse models. Further, there is also a big discrepancy between the number of discovered and functionally characterized lncRNAs. Notably, lncRNAs are not limited to the discussed binding properties in this review and likely have different roles depending on cell type and localization in subcellular compartments that may yet have to be defined. LncRNAs may also exhibit stage-specific roles, but, up to date, research has focused on atherosclerosis progression and information on lncRNAs in resolution of atherosclerosis is scant.

RNA-centered therapeutics in CVDs are already used in the clinics; for example, an RNA interfering agent to treat hypercholesterolemia [88]. Additional clinical trials are 
ongoing, but these do not yet involve lncRNAs [89, 90], as the relative lack of knowledge in the diverse and complex mechanisms of lncRNAs in atherosclerosis hinders its clinical translation. Nonetheless, the rapidly evolving advancements in genomic tools and increasing accomplishments to understand the biology of atherosclerotic lncRNAs hold promise for their clinical translation in the near future.

\section{Compliance with Ethical Standards}

Conflict of Interest The authors have nothing to disclose.

Human and Animal Rights This article does not contain any studies with human or animal subjects performed by any of the authors.

Open Access This article is licensed under a Creative Commons Attribution 4.0 International License, which permits use, sharing, adaptation, distribution and reproduction in any medium or format, as long as you give appropriate credit to the original author(s) and the source, provide a link to the Creative Commons licence, and indicate if changes were made. The images or other third party material in this article are included in the article's Creative Commons licence, unless indicated otherwise in a credit line to the material. If material is not included in the article's Creative Commons licence and your intended use is not permitted by statutory regulation or exceeds the permitted use, you will need to obtain permission directly from the copyright holder. To view a copy of this licence, visit http://creativecommons.org/licenses/by/4.0/.

\section{References}

1. Lander ES, Linton LM, Birren B, Nusbaum C, Zody MC, Baldwin $\mathrm{J}$, et al. Initial sequencing and analysis of the human genome. Nature. 2001;409(6822):860-921. https://doi.org/10.1038/ 35057062 .

2. Venter JC, Adams MD, Myers EW, Li PW, Mural RJ, Sutton GG, et al. The sequence of the human genome. Science. 2001;291(5507):1304-51. https://doi.org/10.1126/science. 1058040.

3. Nabel EG, Braunwald E. A tale of coronary artery disease and myocardial infarction. N Engl J Med. 2012;366(1):54-63. https:// doi.org/10.1056/NEJMra1112570.

4. Bhatnagar P, Wickramasinghe K, Wilkins E, Townsend N. Trends in the epidemiology of cardiovascular disease in the UK. Heart. 2016;102(24):1945-52. https://doi.org/10.1136/heartjnl-2016309573.

5. (WHO) WHO. World Health Statistics. 2017: Monitoring health for the SDGs. Geneva: WHO; 2017.

6. Samani NJ, Erdmann J, Hall AS, Hengstenberg C, Mangino M, Mayer B, et al. Genomewide association analysis of coronary artery disease. N Engl J Med. 2007;357(5):443-53. https://doi.org/10. 1056/NEJMoa072366.

7. McPherson R, Pertsemlidis A, Kavaslar N, Stewart A, Roberts R, Cox DR, et al. A common allele on chromosome 9 associated with coronary heart disease. Science. 2007;316(5830):1488-91. https:// doi.org/10.1126/science.1142447.

8. Helgadottir A, Thorleifsson G, Manolescu A, Gretarsdottir S, Blondal T, Jonasdottir A, et al. A common variant on chromosome 9 p21 affects the risk of myocardial infarction. Science. 2007;316(5830):1491-3. https://doi.org/10.1126/science.1142842.
9. Wellcome Trust Case Control C. Genome-wide association study of 14,000 cases of seven common diseases and 3,000 shared controls. Nature. 2007;447(7145):661-78. https://doi.org/10.1038/ nature05911.

10. Holdt LM, Beutner F, Scholz M, Gielen S, Gabel G, Bergert H, et al. ANRIL expression is associated with atherosclerosis risk at chromosome 9p21. Arterioscler Thromb Vasc Biol. 2010;30(3): 620-7. https://doi.org/10.1161/ATVBAHA.109.196832.

11. Cluett C, McDermott MM, Guralnik J, Ferrucci L, Bandinelli S, Miljkovic I, et al. The 9p21 myocardial infarction risk allele increases risk of peripheral artery disease in older people. Circ Cardiovasc Genet. 2009;2(4):347-53. https://doi.org/10.1161/ CIRCGENETICS.108.825935

12. Murabito JM, White CC, Kavousi M, Sun YV, Feitosa MF, Nambi $\mathrm{V}$, et al. Association between chromosome 9p21 variants and the ankle-brachial index identified by a meta-analysis of 21 genomewide association studies. Circ Cardiovasc Genet. 2012;5(1):100 12. https://doi.org/10.1161/CIRCGENETICS.111.961292.

13. Larson MG, Atwood LD, Benjamin EJ, Cupples LA, D'Agostino RB Sr, Fox CS, et al. Framingham Heart Study 100K project: genome-wide associations for cardiovascular disease outcomes. BMC Med Genet. 2007;8 Suppl 1:S5. https://doi.org/10.1186/ 1471-2350-8-S1-S5.

14. Matarin M, Brown WM, Singleton A, Hardy JA, Meschia JF. Investigators I. Whole genome analyses suggest ischemic stroke and heart disease share an association with polymorphisms on chromosome 9p21. Stroke. 2008;39(5):1586-9. https://doi.org/10. 1161/STROKEAHA.107.502963.

15. Wahlstrand B, Orho-Melander M, Delling L, Kjeldsen S, Narkiewicz K, Almgren P, et al. The myocardial infarction associated CDKN2A/CDKN2B locus on chromosome $9 \mathrm{p} 21$ is associated with stroke independently of coronary events in patients with hypertension. J Hypertens. 2009;27(4):769-73. https://doi.org/10. 1097/HJH.0b013e328326f7eb.

16. Gschwendtner A, Bevan S, Cole JW, Plourde A, Matarin M, RossAdams $\mathrm{H}$, et al. Sequence variants on chromosome 9p21.3 confer risk for atherosclerotic stroke. Ann Neurol. 2009;65(5):531-9. https://doi.org/10.1002/ana.21590.

17. International Stroke Genetics $\mathrm{C}$, Wellcome Trust Case Control $\mathrm{C}$, Bellenguez C, Bevan S, Gschwendtner A, Spencer CC, et al. Genome-wide association study identifies a variant in HDAC9 associated with large vessel ischemic stroke. Nat Genet. 2012;44(3): 328-33. https://doi.org/10.1038/ng.1081.

18. Dichgans M, Malik R, Konig IR, Rosand J, Clarke R, Gretarsdottir $\mathrm{S}$, et al. Shared genetic susceptibility to ischemic stroke and coronary artery disease: a genome-wide analysis of common variants. Stroke. 2014;45(1):24-36. https://doi.org/10.1161/STROKEAHA. 113.002707 .

19. Helgadottir A, Thorleifsson G, Magnusson KP, Gretarsdottir S, Steinthorsdottir V, Manolescu A, et al. The same sequence variant on 9p21 associates with myocardial infarction, abdominal aortic aneurysm and intracranial aneurysm. Nat Genet. 2008;40(2):21724. https://doi.org/10.1038/ng.72.

20. Nelson CP, Goel A, Butterworth AS, Kanoni S, Webb TR, Marouli $\mathrm{E}$, et al. Association analyses based on false discovery rate implicate new loci for coronary artery disease. Nat Genet. 2017;49(9):138591. https://doi.org/10.1038/ng.3913.

21. Cech TR, Steitz JA. The noncoding RNA revolution-trashing old rules to forge new ones. Cell. 2014;157(1):77-94. https://doi.org/ 10.1016/j.cell.2014.03.008.

22. Harrow J, Frankish A, Gonzalez JM, Tapanari E, Diekhans M, Kokocinski F, et al. GENCODE: the reference human genome annotation for The ENCODE Project. Genome Res. 2012;22(9): 1760-74. https://doi.org/10.1101/gr.135350.111. 
23. Palazzo AF, Lee ES. Non-coding RNA: what is functional and what is junk? Front Genet. 2015;6:2. https://doi.org/10.3389/fgene.2015. 00002 .

24. Schmitz SU, Grote P, Herrmann BG. Mechanisms of long noncoding RNA function in development and disease. Cell Mol Life Sci. 2016;73(13):2491-509. https://doi.org/10.1007/s00018-016-21745 .

25. Bhartiya D, Scaria V. Genomic variations in non-coding RNAs: structure, function and regulation. Genomics. 2016;107(2-3):5968. https://doi.org/10.1016/j.ygeno.2016.01.005.

26. Wilhelm M, Schlegl J, Hahne H, Gholami AM, Lieberenz M, Savitski MM, et al. Mass-spectrometry-based draft of the human proteome. Nature. 2014;509(7502):582-7. https://doi.org/10.1038/ nature 13319

27. van Heesch S, Witte F, Schneider-Lunitz V, Schulz JF, Adami E, Faber AB, et al. The translational landscape of the human heart. Cell. 2019;178(1):242-60 e29. https://doi.org/10.1016/j.cell.2019. 05.010 .

28. Mercer TR, Mattick JS. Structure and function of long noncoding RNAs in epigenetic regulation. Nat Struct Mol Biol. 2013;20(3): 300-7. https://doi.org/10.1038/nsmb.2480.

29. Wang KC, Chang HY. Molecular mechanisms of long noncoding RNAs. Mol Cell. 2011;43(6):904-14. https://doi.org/10.1016/j. molcel.2011.08.018.

30. Geisler S, Coller J. RNA in unexpected places: long non-coding RNA functions in diverse cellular contexts. Nat Rev Mol Cell Biol. 2013;14(11):699-712. https://doi.org/10.1038/nrm3679.

31. Pang KC, Frith MC, Mattick JS. Rapid evolution of noncoding RNAs: lack of conservation does not mean lack of function. Trends Genet. 2006;22(1):1-5. https://doi.org/10.1016/j.tig.2005. 10.003 .

32. Guttman M, Amit I, Garber M, French C, Lin MF, Feldser D, et al. Chromatin signature reveals over a thousand highly conserved large non-coding RNAs in mammals. Nature. 2009;458(7235):223-7. https://doi.org/10.1038/nature07672.

33. Makarewich CA, Olson EN. Mining for micropeptides. Trends Cell Biol. 2017;27(9):685-96. https://doi.org/10.1016/j.tcb.2017.04. 006.

34. Li C, Hu Z, Zhang W, Yu J, Yang Y, Xu Z, et al. Regulation of cholesterol homeostasis by a novel long non-coding RNA LASER. Sci Rep. 2019;9(1):7693. https://doi.org/10.1038/s41598-01944195-2.

35. Sallam T, Jones MC, Gilliland T, Zhang L, Wu X, Eskin A, et al. Feedback modulation of cholesterol metabolism by the lipidresponsive non-coding RNA LeXis. Nature. 2016;534(7605): 124-8. https://doi.org/10.1038/nature17674.

36. Tontonoz P, Wu X, Jones M, Zhang Z, Salisbury D, Sallam T. Long noncoding RNA facilitated gene therapy reduces atherosclerosis in a murine model of familial hypercholesterolemia. Circulation. 2017;136(8):776-8. https://doi.org/10.1161/CIRCULATIONAHA. 117.029002 .

37. Li G, Gu HM, Zhang DW. ATP-binding cassette transporters and cholesterol translocation. IUBMB Life. 2013;65(6):505-12. https:// doi.org/10.1002/iub.1165.

38. Sallam T, Jones M, Thomas BJ, Wu X, Gilliland T, Qian K, et al. Transcriptional regulation of macrophage cholesterol efflux and atherogenesis by a long noncoding RNA. Nat Med. 2018;24(3): 304-12. https://doi.org/10.1038/nm.4479.

39. Li H, Han S, Sun Q, Yao Y, Li S, Yuan C, et al. Long non-coding RNA CDKN2B-AS1 reduces inflammatory response and promotes cholesterol efflux in atherosclerosis by inhibiting ADAM10 expression. Aging (Albany NY). 2019;11(6):1695-715. https://doi.org/ 10.18632/aging. 101863

40. Holdt LM, Teupser D. Long noncoding RNA ANRIL: Lnc-ing genetic variation at the chromosome 9p21 locus to molecular mechanisms of atherosclerosis. Front Cardiovasc Med. 2018;5: 145. https://doi.org/10.3389/fcvm.2018.00145.

41. Meng XD, Yao HH, Wang LM, Yu M, Shi S, Yuan ZX, et al. Knockdown of GAS5 inhibits atherosclerosis progression via reducing EZH2-mediated ABCA1 transcription in ApoE(-/-) mice. Mol Ther Nucleic Acids. 2019;19:84-96. https://doi.org/10.1016/j. omtn.2019.10.034.

42. Libby P. Inflammation in atherosclerosis. Arterioscler Thromb Vasc Biol. 2012;32(9):2045-51. https://doi.org/10.1161/ ATVBAHA.108.179705.

43. Hu YW, Guo FX, Xu YJ, Li P, Lu ZF, McVey DG, et al. Long noncoding RNA NEXN-AS1 mitigates atherosclerosis by regulating the actin-binding protein NEXN. J Clin Invest. 2019;129(3): 1115-28. https://doi.org/10.1172/JCI98230.

44. Wu LM, Wu SG, Chen F, Wu Q, Wu CM, Kang CM, et al. Atorvastatin inhibits pyroptosis through the lncRNA NEXN-AS1/ NEXN pathway in human vascular endothelial cells. Atherosclerosis. 2020;293:26-34. https://doi.org/10.1016/j. atherosclerosis.2019.11.033.

45. Leisegang MS, Fork C, Josipovic I, Richter FM, Preussner J, Hu J, et al. Long noncoding RNA MANTIS facilitates endothelial angiogenic function. Circulation. 2017;136(1):65-79. https://doi.org/10. 1161/CIRCULATIONAHA.116.026991.

46. Leisegang MS, Bibli SI, Gunther S, Pfluger-Muller B, Oo JA, Hoper C, et al. Pleiotropic effects of laminar flow and statins depend on the Kruppel-like factor-induced lncRNA MANTIS. Eur Heart J. 2019;40(30):2523-33. https://doi.org/10.1093/eurheartj/ ehz393.

47. Khyzha N, Khor M, DiStefano PV, Wang L, Matic L, Hedin U, et al. Regulation of CCL2 expression in human vascular endothelial cells by a neighboring divergently transcribed long noncoding RNA. Proc Natl Acad Sci U S A. 2019;116(33):16410-9. https:// doi.org/10.1073/pnas.1904108116.

48. Gomez D, Owens GK. Smooth muscle cell phenotypic switching in atherosclerosis. Cardiovasc Res. 2012;95(2):156-64. https://doi. org $/ 10.1093 /$ cvr/cvs115.

49. Ahmed ASI, Dong K, Liu J, Wen T, Yu L, Xu F, et al. Long noncoding RNA NEAT1 (nuclear paraspeckle assembly transcript 1 ) is critical for phenotypic switching of vascular smooth muscle cells. Proc Natl Acad Sci U S A. 2018;115(37):E8660-E7. https:// doi.org/10.1073/pnas.1803725115.

50. Haemmig S, Yang D, Sun X, Das D, Ghaffari S, Molinaro R, et al. Long noncoding RNA SNHG12 integrates a DNA-PK-mediated DNA damage response and vascular senescence. Sci Transl Med. 2020;12(531). https://doi.org/10.1126/scitranslmed.aaw1868.

51. Quinodoz S, Guttman M. Long noncoding RNAs: an emerging link between gene regulation and nuclear organization. Trends Cell Biol. 2014;24(11):651-63. https://doi.org/10.1016/j.tcb.2014.08. 009 .

52. Guo FX, Wu Q, Li P, Zheng L, Ye S, Dai XY, et al. The role of the LncRNA-FA2H-2-MLKL pathway in atherosclerosis by regulation of autophagy flux and inflammation through mTOR-dependent signaling. Cell Death Differ. 2019;26(9):1670-87. https://doi.org/10. 1038/s41418-018-0235-Z.

53. Liao X, Sluimer JC, Wang Y, Subramanian M, Brown K, Pattison JS, et al. Macrophage autophagy plays a protective role in advanced atherosclerosis. Cell Metab. 2012;15(4):545-53. https://doi.org/10. 1016/j.cmet.2012.01.022

54. Grootaert MO, da Costa Martins PA, Bitsch N, Pintelon I, De Meyer GR, Martinet W, et al. Defective autophagy in vascular smooth muscle cells accelerates senescence and promotes neointima formation and atherogenesis. Autophagy. 2015;11(11):2014 32. https://doi.org/10.1080/15548627.2015.1096485.

55. Dai S, Wang B, Li W, Wang L, Song X, Guo C, et al. Systemic application of 3-methyladenine markedly inhibited atherosclerotic lesion in $\mathrm{ApoE}(-/-)$ mice by modulating autophagy, foam cell 
formation and immune-negative molecules. Cell Death Dis. 2016;7(12):e2498. https://doi.org/10.1038/cddis.2016.376.

56. Fan X, Wang J, Hou J, Lin C, Bensoussan A, Chang D, et al. Berberine alleviates ox-LDL induced inflammatory factors by upregulation of autophagy via AMPK/mTOR signaling pathway. $\mathrm{J}$ Transl Med. 2015;13:92. https://doi.org/10.1186/s12967-0150450-z.

57. Rashid F, Shah A, Shan G. Long non-coding RNAs in the cytoplasm. Genomics Proteomics Bioinformatics. 2016;14(2):73-80. https://doi.org/10.1016/j.gpb.2016.03.005.

58. Mahmoud AD, Ballantyne MD, Miscianinov V, Pinel K, Hung J, Scanlon JP, et al. The human-specific and smooth muscle cellenriched LncRNA SMILR promotes proliferation by regulating mitotic CENPF mRNA and drives cell-cycle progression which can be targeted to limit vascular remodeling. Circ Res. 2019;125(5):535-51. https://doi.org/10.1161/CIRCRESAHA.119. 314876.

59. Ballantyne MD, Pinel K, Dakin R, Vesey AT, Diver L, Mackenzie $\mathrm{R}$, et al. Smooth muscle enriched Long noncoding RNA (SMILR) regulates cell proliferation. Circulation. 2016;133(21):2050-65. https://doi.org/10.1161/CIRCULATIONAHA.115.021019.

60. Hennessy EJ, van Solingen C, Scacalossi KR, Ouimet M, Afonso MS, Prins J, et al. The long noncoding RNA CHROME regulates cholesterol homeostasis in primate. Nat Metab. 2019;1(1):98-110. https://doi.org/10.1038/s42255-018-0004-9.

61. Hu YW, Zhao JY, Li SF, Huang JL, Qiu YR, Ma X, et al. RP5833A20.1/miR-382-5p/NFIA-dependent signal transduction pathway contributes to the regulation of cholesterol homeostasis and inflammatory reaction. Arterioscler Thromb Vasc Biol. 2015;35(1):87-101. https://doi.org/10.1161/ATVBAHA.114. 304296.

62. Zhen Z, Ren S, Ji H, Ding X, Zou P, Lu J. The lncRNA DAPK-IT1 regulates cholesterol metabolism and inflammatory response in macrophages and promotes atherogenesis. Biochem Biophys Res Commun. 2019;516(4):1234-41. https://doi.org/10.1016/j.bbrc. 2019.06.113

63. Shen S, Zheng X, Zhu Z, Zhao S, Zhou Q, Song Z, et al. Silencing of GAS5 represses the malignant progression of atherosclerosis through upregulation of miR-135a. Biomed Pharmacother. 2019;118:109302. https://doi.org/10.1016/j.biopha.2019.109302.

64. Du XJ, Lu JM. MiR-135a represses oxidative stress and vascular inflammatory events via targeting toll-like receptor 4 in atherogenesis. J Cell Biochem. 2018;119(7):6154-61. https://doi.org/10. 1002/jcb.26819.

65. Ye J, Wang C, Wang D, Yuan H. LncRBA GSA5, up-regulated by ox-LDL, aggravates inflammatory response and MMP expression in THP-1 macrophages by acting like a sponge for miR-221. Exp Cell Res. 2018;369(2):348-55. https://doi.org/10.1016/j.yexcr. 2018.05.039.

66. Chen L, Yao H, Hui JY, Ding SH, Fan YL, Pan YH, et al. Global transcriptomic study of atherosclerosis development in rats. Gene. 2016;592(1):43-8. https://doi.org/10.1016/j.gene.2016.07.023.

67. Michalik KM, You X, Manavski Y, Doddaballapur A, Zornig M, Braun T, et al. Long noncoding RNA MALAT1 regulates endothelial cell function and vessel growth. Circ Res. 2014;114(9):138997. https://doi.org/10.1161/CIRCRESAHA.114.303265.

68. Brock M, Schuoler C, Leuenberger C, Buhlmann C, Haider TJ, Vogel J, et al. Analysis of hypoxia-induced noncoding RNAs reveals metastasis-associated lung adenocarcinoma transcript 1 as an important regulator of vascular smooth muscle cell proliferation. Exp Biol Med (Maywood). 2017;242(5):487-96. https://doi.org/ $10.1177 / 1535370216685434$

69. Wang K, Yang C, Shi J, Gao T. Ox-LDL-induced lncRNA MALAT1 promotes autophagy in human umbilical vein endothelial cells by sponging miR-216a-5p and regulating Beclin-1 expression. Eur J Pharmacol. 2019;858:172338. https://doi.org/ 10.1016/j.ejphar.2019.04.019.

70. Song Y, Yang L, Guo R, Lu N, Shi Y, Wang X. Long noncoding RNA MALAT1 promotes high glucose-induced human endothelial cells pyroptosis by affecting NLRP3 expression through competitively binding miR-22. Biochem Biophys Res Commun. 2019;509(2):359-66. https://doi.org/10.1016/j.bbrc.2018.12.139.

71. Cremer S, Michalik KM, Fischer A, Pfisterer L, Jae N, Winter C, et al. Hematopoietic deficiency of the long noncoding RNA MALAT1 promotes atherosclerosis and plaque inflammation. Circulation. 2019;139(10):1320-34. https://doi.org/10.1161/ CIRCULATIONAHA.117.029015.

72. Salmena L, Poliseno L, Tay Y, Kats L, Pandolfi PP. A ceRNA hypothesis: the Rosetta stone of a hidden RNA language? Cell. 2011;146(3):353-8. https://doi.org/10.1016/j.cell.2011.07.014.

73. Denzler R, Agarwal V, Stefano J, Bartel DP, Stoffel M. Assessing the ceRNA hypothesis with quantitative measurements of miRNA and target abundance. Mol Cell. 2014;54(5):766-76. https://doi. org/10.1016/j.molcel.2014.03.045.

74. Wang M, Li C, Zhang Y, Zhou X, Liu Y, Lu C. LncRNA MEG3derived miR-361-5p regulate vascular smooth muscle cells proliferation and apoptosis by targeting ABCA1. Am J Transl Res. 2019;11(6):3600-9.

75. Xu D, Liu T, He L, Han D, Ma Y, Du J. LncRNA MEG3 inhibits HMEC-1 cells growth, migration and tube formation via sponging miR-147. Biol Chem. 2020;401:601-15. https://doi.org/10.1515/ hsz-2019-0230.

76. Lu W, Huang SY, Su L, Zhao BX, Miao JY. Long noncoding RNA LOC100129973 suppresses apoptosis by targeting miR-4707-5p and miR-4767 in vascular endothelial cells. Sci Rep. 2016;6: 21620. https://doi.org/10.1038/srep21620.

77. Lu W, He X, Su L, Miao J. Long noncoding RNA-CERNA1 stabilized atherosclerotic plaques in apolipoprotein $\mathrm{E}(-/-)$ mice. $\mathrm{J}$ Cardiovasc Transl Res. 2019;12(5):425-34. https://doi.org/10. 1007/s12265-019-09883-4.

78. Ye ZM, Yang S, Xia YP, Hu RT, Chen S, Li BW, et al. LncRNA MIAT sponges miR-149-5p to inhibit efferocytosis in advanced atherosclerosis through CD47 upregulation. Cell Death Dis. 2019;10(2):138. https://doi.org/10.1038/s41419-019-1409-4.

79. Wu X, Zheng X, Cheng J, Zhang K, Ma C. LncRNA TUG1 regulates proliferation and apoptosis by regulating miR-148b/IGF2 axis in ox-LDL-stimulated VSMC and HUVEC. Life Sci. 2020;243: 117287. https://doi.org/10.1016/j.lfs.2020.117287.

80. Zhang L, Cheng H, Yue Y, Li S, Zhang D, He R. TUG1 knockdown ameliorates atherosclerosis via up-regulating the expression of miR-133a target gene FGF1. Cardiovasc Pathol. 2018;33:6-15. https://doi.org/10.1016/j.carpath.2017.11.004.

81. Zhu X, Liu Y, Yu J, Du J, Guo R, Feng Y, et al. LncRNA HOXAAS2 represses endothelium inflammation by regulating the activity of NF-kappaB signaling. Atherosclerosis. 2019;281:38-46. https:// doi.org/10.1016/j.atherosclerosis.2018.12.012.

82. Hung J, Scanlon JP, Mahmoud AD, Rodor J, Ballantyne M, Fontaine MAC, et al. Novel plaque enriched Long noncoding RNA in atherosclerotic macrophage regulation (PELATON). Arterioscler Thromb Vasc Biol. 2020;40(3):697-713. https://doi. org/10.1161/ATVBAHA.119.313430.

83. Pan JX. LncRNA H19 promotes atherosclerosis by regulating MAPK and NF-kB signaling pathway. Eur Rev Med Pharmacol Sci. 2017;21(2):322-8

84. Zhang Z, Gao W, Long QQ, Zhang J, Li YF, Liu DC, et al. Increased plasma levels of lncRNA H19 and LIPCAR are associated with increased risk of coronary artery disease in a Chinese population. Sci Rep. 2017;7(1):7491. https://doi.org/10.1038/ s41598-017-07611-z.

85. Zhu M, Li N, Luo P, Jing W, Wen X, Liang C, et al. Peripheral blood leukocyte expression of lncRNA MIAT and its diagnostic 
and prognostic value in ischemic stroke. J Stroke Cerebrovasc Dis. 2018;27(2):326-37. https://doi.org/10.1016/j.jstrokecerebrovasdis. 2017.09.009.

86. Ma R, He X, Zhu X, Pang S, Yan B. Promoter polymorphisms in the IncRNA-MIAT gene associated with acute myocardial infarction in Chinese Han population: a case-control study. Biosci Rep. 2020;40(2). https://doi.org/10.1042/BSR20191203.

87. Wang G, Li Y, Peng Y, Tang J, Li H. Association of polymorphisms in MALAT1 with risk of coronary atherosclerotic heart disease in a Chinese population. Lipids Health Dis. 2018;17(1): 75. https://doi.org/10.1186/s12944-018-0728-2.

88. Fitzgerald K, White S, Borodovsky A, Bettencourt BR, Strahs A, Clausen V, et al. A highly durable RNAi therapeutic inhibitor of
PCSK9. N Engl J Med. 2017;376(1):41-51. https://doi.org/10. 1056/NEJMoa1609243.

89. Pham TP, Kremer V, Boon RA. RNA-based therapeutics in cardiovascular disease. Curr Opin Cardiol. 2020;35(3):191-8. https://doi. org/10.1097/HCO.0000000000000724.

90. Holdt LM, Kohlmaier A, Teupser D. Long noncoding RNAs of the arterial wall as therapeutic agents and targets in atherosclerosis. Thromb Haemost. 2019;119(8):1222-36. https://doi.org/10.1055/ s-0039-1692680.

Publisher's Note Springer Nature remains neutral with regard to jurisdictional claims in published maps and institutional affiliations. 